\title{
Polarization properties of aerosol particles over western Japan: classification, seasonal variation, and implications for air quality
}

Xiaole Pan et al.

Correspondence to: Xiaole Pan (panxiaole@ mail.iap.ac.cn)

The copyright of individual parts of the supplement might differ from the CC-BY 3.0 licence. 


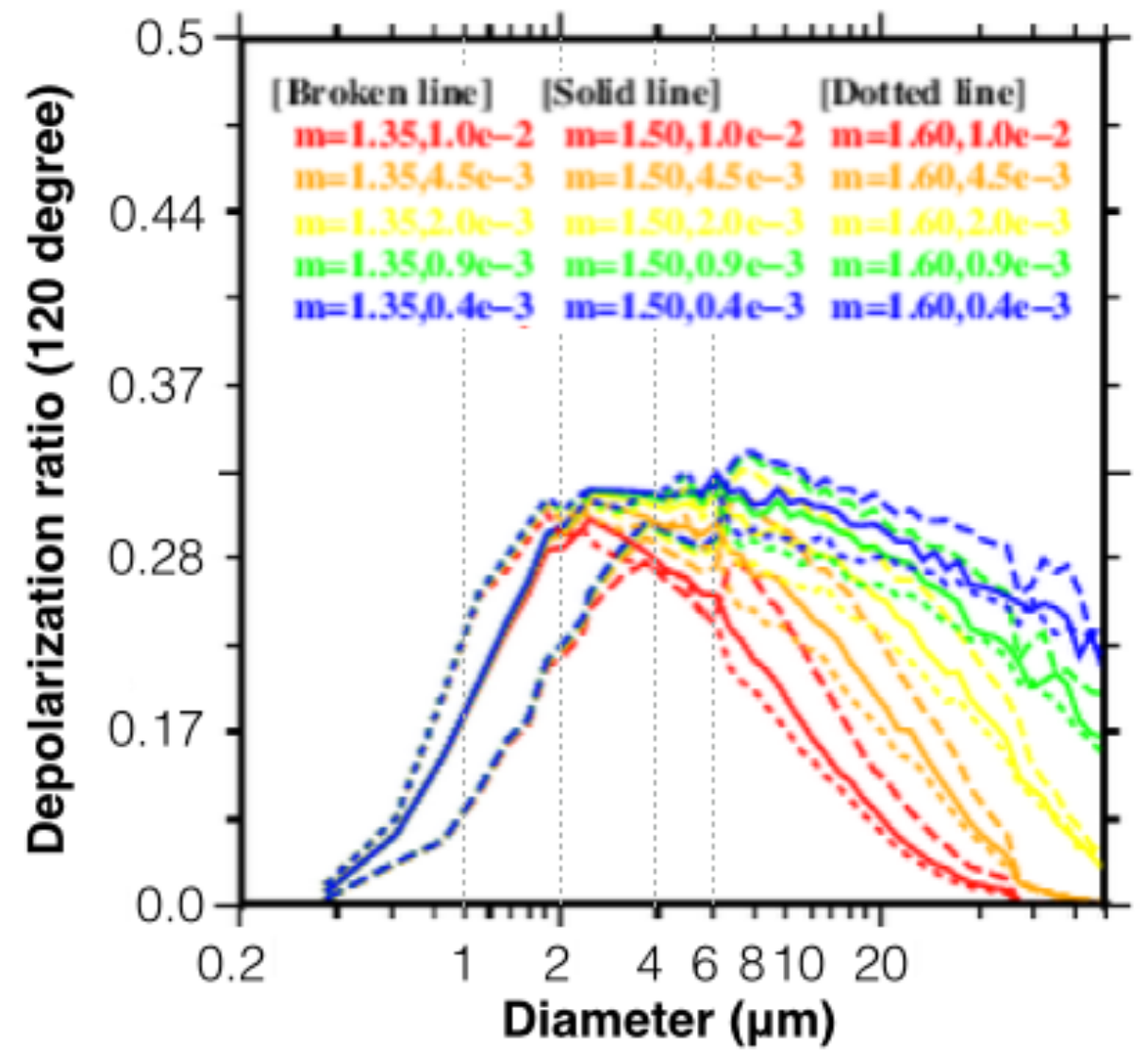

SF.1 Theoretical calculation of depolarization ratio (at 120 backward direction) as a function of particle size for different refractive index. The simulation was on the basis of particles of Voronoi aggregation. 

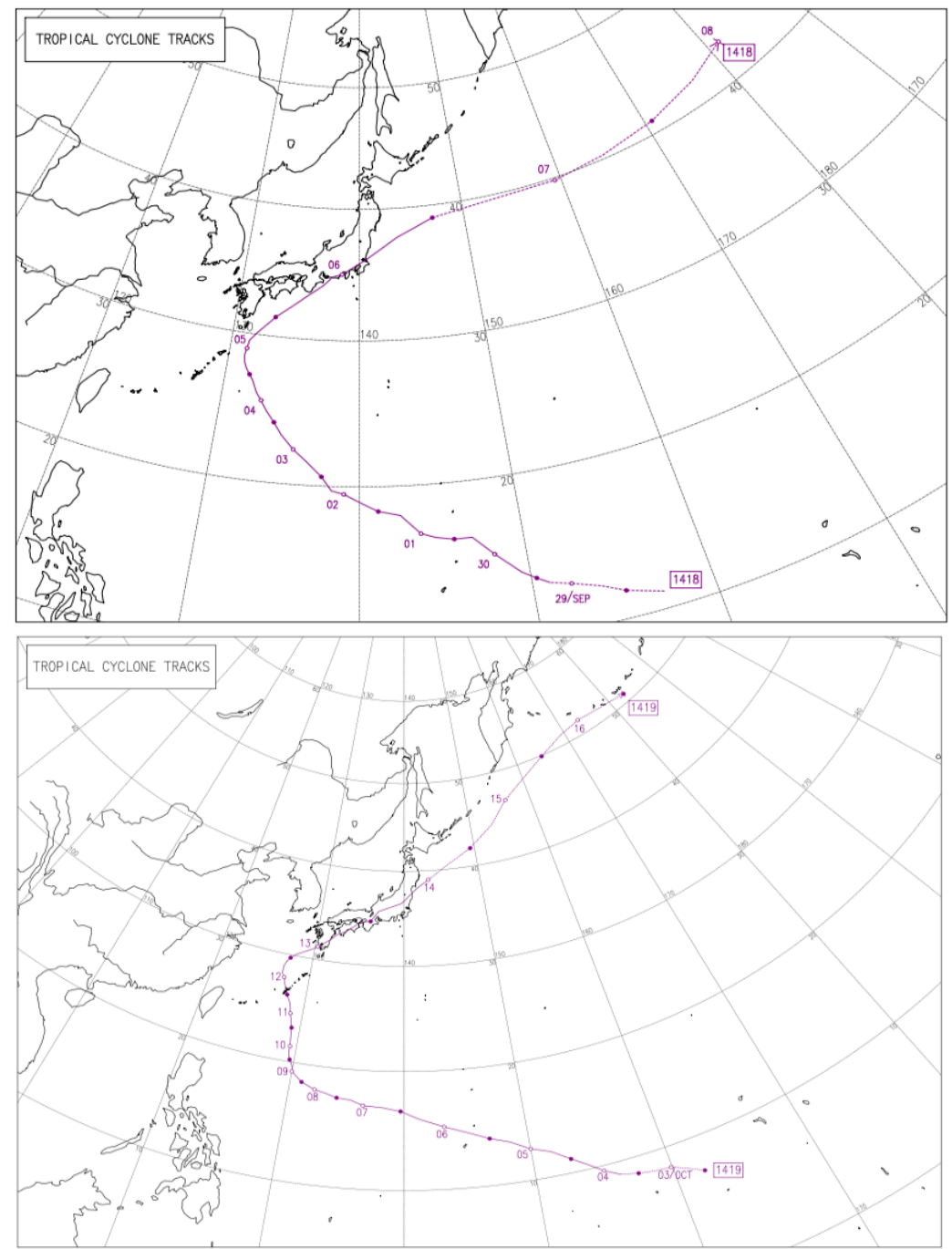

SF. 2 The geographic positions of typhoon center on $4^{\text {th }}$ Oct and $13^{\text {th }}$ Oct, 2014. No. 18 Phanfone and No. 19 Vongfong) during the study period is provided on the Japan Meteorological Agency webpage (http://www.data.jma.go.jp/fcd/yoho/typhoon/route_map/index.html 